\title{
Multicriteria Decision Support System for Selecting the Structural and Functional Scheme of a Biogas Plant in the Agro-Industrial Complex
}

\author{
Valery Lubentsov*, Ekaterina Ozhogova, Elena Lubentsova, and Evgeniy Shakhray \\ Kuban State Technological University, 2 Moskovskaya Street, Krasnodar, Russia, 350972
}

\begin{abstract}
The variants of structural and functional schemes of biogas plants (BP) were investigated to obtain biogas and fertilizers based on the processing of solid organic waste in the agro-industrial complex (AIC). Based on the results of the study of biogas technologies, criteria are proposed for determining the best layout from the expert's point of view. The systematization of options is given and alternatives are obtained. The method of multicriteria analysis of options based on fuzzy sets was used as a decision-making method. The use of the decision support system to select the best variant of the structural and functional scheme of the biogas plant predetermined the formation of a matrix of paired comparisons of dimension $5 \times 5$. To ensure high consistency of preferences associated with the procedure for filling in the matrices of paired comparisons of alternatives according to criteria, the method developed by us has been applied. This reduces the number of inquiries to the decision-maker. The selected structural and functional scheme meets the requirements for the development of typical automation solutions, which contributes to the replication of control systems for the same type of plants.
\end{abstract}

\section{Introduction}

To date, many technological schemes of biogas plants (BP) have been developed [1]. Farmers wishing to purchase a biogas plant are faced with the need to conduct an in-depth analysis of all the technologies presented in order to determine the most economically profitable and climatically suitable solution. This item complicates significantly the process of introducing biogas technologies in this region and leads to the need to select a rational technological scheme and equipment for obtaining biogas from animal waste for specific conditions, which will ensure maximum efficiency of the process at minimum cost. Since the choice of a structural and functional scheme for biogas production cannot be carried out using one criterion, independently of the others, which are in significant relationships and connections with each other, it is necessary to investigate the multicriteria selection problem. The lack of recommendations determines the task of supporting decision-making when choosing layout schemes for biogas plants in the agro-industrial complex, taking into

\footnotetext{
* Corresponding author: vf.lubentsov@yandex.ru
} 
account the influence of a large number of factors as relevant, largely determining the development of an effective control system for the biogas production process.

The relevance of the problem under consideration is confirmed by a number of solutions for the implementation of projects in the field of alternative energy in the Krasnodar Region [2]. It is bioenergy, one of the important renewable energy sources, which provides for the use of biogas plants by agricultural enterprises for processing animal waste into heat, which, as noted in [3], is an excellent solution both for energy supply and for improving the environment in all the Region.

\section{Comparative analysis of existing biogas plant options and formation of comparison criteria}

When choosing a layout diagram of a biogas plant, an analysis of options for existing technologies and equipment for their implementation was carried out. If the layout of the biogas plant does not minimize the risks associated with the violation of the conditions for the preparation of raw materials, the heating and supply system of the substrate, the temperature regime during the fermentation process and the operation of the gasholder, then these schemes are excluded from consideration as making a desperate play. With this in mind, the schemes of the BioMash-20 biogas plant by the Klimov Design Bureau, the SBG series units produced by the SelkhozBioGaz company from Kirov, the BIO series units manufactured by the Agrobiogas company, the BGR series units manufactured by the BioGasRussia enterprise located in Yaransk and a series of installations BUG by the BMP association of enterprises supplied by domestic firms, were considered. [4, 5]. In the problem under consideration, we will conventionally refer a BP of this type to BP1-BP5, respectively.

Equipment for the preparation and preliminary processing of raw materials for mixing the substrate, grinding, separation of impurities at the entrance to the bioreactor, loading (supply and dosing) of the fermentation suspension in the compared BP1-BP3 is conventionally assumed to be the same, in BP4-BP5 - absent.

Based on the results of the analysis of biogas technologies, the criteria for determining the best layout from the point of view of an expert were considered. The energy criterion is associated with the production of biofuels and the production of liquid ecological fertilizers (LEF) or the production of only one of them. The environmental criterion is associated with the creation of waste-free production facilities, reduction of "greenhouse" emissions, obtaining environmentally friendly LEF or their insignificant impact on the environment. The economic criterion is associated with the increase in productivity and in soil fertility, and their ecological purity. In this case, produced biogas can be sent to power plants for the generation of electricity and heat. Therefore, there is no need to purchase electricity, heat, organic fertilizers from any third-party manufacturers.

The efficiency of digestion tanks is characterized by the productivity of gas and fertilizers. The implementation of the installation is characterized by a modular design principle, the mode of operation of the bioreactor, the type of heat supply and substrate mixing system, the possibility of increasing the number of bioreactors to increase productivity. Each of these criteria includes several assessments. It is necessary to note that the possible options differ not only in the given characteristics. For a preliminary assessment, in this paper, only those were taken that really influence the choice. Additional criteria, of course, may be different, but for each of them, in any case, it should be possible to collect information.

Comparison of the proposed criteria is shown in Table 1 . Alternative variants of the layout schemes, adapted to the above-mentioned BP, are presented in Table 2. 
Table 1. Comparison criteria for biogas plants.

\begin{tabular}{|c|c|c|c|c|c|}
\hline \multirow{2}{*}{$\begin{array}{l}\text { Name of } \\
\text { criterion }\end{array}$} & \multicolumn{5}{|c|}{ Biogas plants (BP) } \\
\hline & BP1 & BP2 & BP3 & BP4 & BP5 \\
\hline 1 & 2 & 3 & 4 & 5 & 6 \\
\hline $\begin{array}{l}\text { Energy } \\
\left(\mathrm{K}_{1}\right)\end{array}$ & $\begin{array}{l}\text { possibility of } \\
\text { biofuel and } \\
\text { LEF } \\
\text { production }\end{array}$ & $\begin{array}{l}\text { possibility of } \\
\text { biofuel and } \\
\text { LEF } \\
\text { production }\end{array}$ & $\begin{array}{l}\text { possibility of } \\
\text { biofuel } \\
\text { production }\end{array}$ & $\begin{array}{l}\text { possibility of } \\
\text { biofuel and } \\
\text { LEF } \\
\text { production }\end{array}$ & $\begin{array}{l}\text { possibility of } \\
\text { biofuel } \\
\text { production }\end{array}$ \\
\hline $\begin{array}{l}\text { Environ } \\
\text { mental } \\
\left(\mathrm{K}_{2}\right)\end{array}$ & $\begin{array}{l}\text { possibility of } \\
\text { creating } \\
\text { waste-free } \\
\text { production } \\
\text { facilities, } \\
\text { reduction of } \\
\text { greenhouse } \\
\text { emissions and } \\
\text { obtaining } \\
\text { environmental } \\
\text { ly friendly } \\
\text { LEF }\end{array}$ & $\begin{array}{l}\text { possibility of } \\
\text { reduction of } \\
\text { greenhouse } \\
\text { emissions and } \\
\text { obtaining } \\
\text { environmental } \\
\text { ly friendly } \\
\text { LEF }\end{array}$ & $\begin{array}{l}\text { possibility of } \\
\text { creating } \\
\text { waste-free } \\
\text { production } \\
\text { facilities }\end{array}$ & $\begin{array}{l}\text { possibility of } \\
\text { creating } \\
\text { waste-free } \\
\text { production } \\
\text { facilities, } \\
\text { reduction of } \\
\text { greenhouse } \\
\text { emissions and } \\
\text { obtaining } \\
\text { environmental } \\
\text { ly friendly } \\
\text { LEF }\end{array}$ & $\begin{array}{l}\text { possibility of } \\
\text { creating } \\
\text { waste-free } \\
\text { production } \\
\text { facilities }\end{array}$ \\
\hline $\begin{array}{l}\text { Economi } \\
\text { c }\left(\mathrm{K}_{3}\right)\end{array}$ & $\begin{array}{l}\text { significant } \\
\text { increase in } \\
\text { productivity, } \\
\text { increase in soil } \\
\text { fertility and its } \\
\text { ecological } \\
\text { safety }\end{array}$ & $\begin{array}{l}\text { high increase } \\
\text { in } \\
\text { productivity, } \\
\text { increase in soil } \\
\text { fertility and its } \\
\text { ecological } \\
\text { safety }\end{array}$ & $\begin{array}{l}\text { low increase } \\
\text { in } \\
\text { productivity, } \\
\text { increase in soil } \\
\text { fertility and its } \\
\text { ecological } \\
\text { safety }\end{array}$ & $\begin{array}{l}\text { significant } \\
\text { increase in } \\
\text { productivity, } \\
\text { increase in soil } \\
\text { fertility and its } \\
\text { ecological } \\
\text { safety }\end{array}$ & $\begin{array}{l}\text { moderate } \\
\text { increase in } \\
\text { productivity, } \\
\text { increase in soil } \\
\text { fertility and its } \\
\text { ecological } \\
\text { safety }\end{array}$ \\
\hline $\begin{array}{l}\text { Efficien } \\
\text { cy of } \\
\text { using } \\
\text { digestio } \\
\mathrm{n} \text { tanks } \\
\left(\mathrm{K}_{4}\right)\end{array}$ & $\begin{array}{l}\text { low } \\
\text { productivity of } \\
\text { gas and } \\
\text { fertilizer }\end{array}$ & $\begin{array}{l}\text { low } \\
\text { productivity of } \\
\text { gas and } \\
\text { fertilizer }\end{array}$ & $\begin{array}{l}\text { high } \\
\text { productivity of } \\
\text { gas and } \\
\text { fertilizer }\end{array}$ & $\begin{array}{l}\text { very high } \\
\text { productivity of } \\
\text { gas }\end{array}$ & $\begin{array}{l}\text { average } \\
\text { productivity of } \\
\text { gas }\end{array}$ \\
\hline $\begin{array}{l}\text { Impleme } \\
\text { ntation } \\
\text { of plant } \\
\left(\mathrm{K}_{5}\right) \\
\end{array}$ & $\begin{array}{l}\text { best (building- } \\
\text { block concept) }\end{array}$ & good & good & close to best & low \\
\hline
\end{tabular}

Table 2. Alternative options for the layout of the BP.

\begin{tabular}{|c|c|c|}
\hline No. & Reference & Options for the layout of the BP \\
\hline 1 & $A_{1}$ & option close in criteria to BP1 \\
\hline 2 & $A_{2}$ & option close in criteria to BP2 \\
\hline 3 & $A_{3}$ & option close in criteria to BP3 \\
\hline 4 & $A_{4}$ & option close in criteria to BP4 \\
\hline 5 & $A_{5}$ & option close in criteria to BP5 \\
\hline
\end{tabular}

As a decision-making method, the method of multi-criteria analysis of options based on fuzzy sets was chosen [6]. Suppose we know the following:

$\boldsymbol{A}=\left\{A_{1}, A_{2}, \ldots ., A_{k}\right\}-$ a set of BP layouts (in this case, $k=1 \ldots 5$ );

$\boldsymbol{K}=\left\{K_{1}, K_{2}, \ldots K_{k}\right\}-$ a set of quantitative and qualitative criteria for evaluating BP layouts (in this case, $k=1 \ldots 5$ ). 
The multicriteria analysis of alternatives consists in ordering the elements of the set $\boldsymbol{A}$ according to the criteria $\boldsymbol{K}$. When developing a decision-making model, we will take into account the following features:

1. When making a decision, it is important to determine the advantages of one option over others. The use of paired comparisons of such alternatives as "according to the $K_{1}$ criterion, the first option $A_{1}$ is superior to the second $A_{2}$ " is more convenient for an expert than determining the absolute values of the criteria for each option.

2. For different technological layouts of BP, the importance of the criteria will be different, but not always essential. Knowledge about the importance of the criteria is reflected in expert statements, for example, the environmental criterion is much more important than the "Convenience of service and operation" criterion.

\section{Methodology for researching the decision-making process when choosing the preferred layout of a biogas plant}

We denote a number from the interval $[0,1]$ as $\mu_{k i}\left(A_{j}\right)$, by which the option of the BP layout $A_{j} \in \boldsymbol{A}$ is estimated according to the criterion $K_{j} \in \boldsymbol{K}$ : the larger the number $\mu_{k j}\left(A_{j}\right)$, the better the option $A_{j}$ according to the criterion $K_{J}, j=1, k, J=1, n$. Then, the criterion $K_{i}$ can be represented by a fuzzy set $\tilde{K}_{i}$ on the universal set of options $\boldsymbol{A}$ :

$$
\tilde{K}_{i}=\left\{\frac{\mu_{k_{1}}\left(A_{1}\right)}{A_{1}}, \frac{\mu_{k_{2}}\left(A_{2}\right)}{A_{2}}, \ldots, \frac{\mu_{k_{i}}\left(A_{k}\right)}{A_{k}}\right\},
$$

where $\mu_{k i}\left(A_{k}\right)$ - degree of belonging of the element $A_{k}$ to a fuzzy set.

It is advisable to determine the degrees of membership of a fuzzy set (1) by the method of membership functions construction based on paired comparisons [7]. The pairwise comparison matrix $\boldsymbol{A}$ is diagonal $\left(\alpha_{i j}=1\right)$ and antisymmetric $\left(\alpha_{i j}=\alpha_{i j}{ }^{-1}, i, j=\overline{1, k}\right)$. The degrees of membership of the fuzzy set (1) correspond to the coordinates of the eigenvector $\boldsymbol{W}=\left(w_{1}, w_{2}, \ldots, w_{k}\right)^{T}$ of the matrix $\boldsymbol{A}: \mu_{k i}\left(A_{j}\right)=w_{j}, j=1, \ldots, k, \mu_{G}\left(P_{j}\right)=w_{j}, j=\overline{1, k}$. The eigenvector $W$ is found using the following system of equations:

$$
(A-\lambda E) \cdot W=0 \text {, }
$$

where $\boldsymbol{W}$ - the eigenvector; $\lambda$ - eigenvalue of matrix $\boldsymbol{A}$.

According to the Bellman and Zadeh's principle [8], the best alternative is the one that meets all the criteria to the greatest extent at the same time. A fuzzy solution is the transverse of particular criteria [9]:

$$
\tilde{D}=\tilde{K}_{1}^{\alpha_{1}} \cap \tilde{K}_{2}^{\alpha_{2}} \cap \ldots \cap \tilde{K}_{n}^{\alpha_{n}}=\left\{\frac{\min \left(\mu_{k_{i}}^{\alpha_{i}}\left(A_{1}\right)\right)}{A_{1}}, \frac{\min \left(\mu_{k_{i}}^{\alpha_{i}}\left(A_{2}\right)\right)}{A_{2}}, \ldots, \frac{\min _{i=1, n}\left(\mu_{k_{i}}^{\alpha_{i}}\left(A_{k}\right)\right)}{A_{k}}\right\},
$$

where $\alpha_{i}$ - coefficient of relative importance of the criterion $K_{i}$, with $\alpha_{1}+\alpha_{2}+\ldots+\alpha_{n}$ $=1$.

The exponent $\alpha_{i}$ in formula (3) concentrates the function of membership of the fuzzy set $K_{i}$ in accordance with the importance of the criterion $K_{i}$. The coefficients of the relative importance of the criteria can be determined using the method of paired comparisons by T. Saaty [7]. According to the fuzzy solution (3), the best option will be the option with the maximum degree of membership $D=\arg \max \left(\mu_{D}\left(A_{1}\right), \mu_{D}\left(A_{2}\right), \ldots, \mu_{D}\left(A_{k}\right)\right)$. 
Let us consider the methodology for selecting layouts based on fuzzy sets developed and adapted to the problem of choosing the layout schemes of the BP. The comparison matrix of the five criteria and its eigenvector are shown in Table 3.

Table 3. Numerical estimates of the pairwise comparison matrix for criteria.

\begin{tabular}{|c|c|c|c|c|c|c|c|}
\hline Criteria & $K_{1}$ & $K_{2}$ & $K_{3}$ & $K_{4}$ & $K_{5}$ & $\begin{array}{l}\text { Assessment } \\
\text { of } \\
\text { eigenvector } \\
\text { components }\end{array}$ & $\begin{array}{c}\text { Normalized } \\
\text { priority } \\
\text { vector } \\
\text { estimates }\end{array}$ \\
\hline$K_{1}$ & 1 & 1 & 2 & 6 & 7 & 2.42580 & 0.33798 \\
\hline$K_{2}$ & 1 & 1 & 2 & 5 & 7 & 2.33894 & 0.32588 \\
\hline$K_{3}$ & $1 / 2$ & $1 / 2$ & 1 & 8 & 9 & 1.78260 & 0.24836 \\
\hline$K_{4}$ & $1 / 6$ & $1 / 5$ & $1 / 8$ & 1 & 1 & 0.33416 & 0.04656 \\
\hline$K_{5}$ & $1 / 7$ & $1 / 7$ & $1 / 9$ & 1 & 1 & 0.29588 & 0.04122 \\
\hline Total & 2.8095 & 2.8429 & 6.2361 & 21.0000 & 25.0000 & 7.17738 & 1.00000 \\
\hline
\end{tabular}

Taking into account the analysis of existing domestic schemes of biogas technologies, let us compare five options of $\mathrm{BP} A_{1} \div A_{5}$ according to the criteria $K_{1} \div K_{5}$. Paired comparisons are made in terms of the dominance of one element of the model over another. The initial information used in the general case can be inaccurate, incomplete and contradictory. To check the consistency of the initial information, taking into account that the random consistency for a matrix of paired comparisons with the dimension of $5 \times 5$ is equal to 1.12 [7], the priority vector, the maximum eigenvalue $\lambda_{\max }$, conformity index (CI), and conformity relation (CR) were calculated. If the CR obtained makes $<10 \%$, there is no need to revise the experts' statements [7]. The use of the method developed by us to ensure high consistency of preferences at all stages associated with the procedure for filling in matrices of paired comparisons of alternatives by criteria can significantly reduce the number of requests to the decision maker [10].

The degrees of membership of the fuzzy set (1) correspond to the coordinates of the eigenvector $\boldsymbol{W}=\left(w_{1}, w_{2}, \ldots, w_{k}\right)^{T}$ of the matrix $\boldsymbol{A}: \mu_{k i}\left(A_{j}\right)=w_{j}, j=1, \ldots, k$, $\mu_{G}\left(P_{j}\right)=w_{j}, j=\overline{1, k}$. The eigenvector $W$ is found using the following system of equations (2).

As a result of the system solution, we obtain the coordinates of the weight eigenvector $w_{1}=$ $0.334, w_{2}=0.325, w_{3}=0.254, w_{4}=0.0462, w_{5}=0.0402$.

Applying formula (2) to equation (1), we obtain the following fuzzy sets:

$$
\begin{aligned}
K_{1} & =\left\{\frac{0.565}{A_{1}}, \frac{0.199}{A_{2}}, \frac{0.113}{A_{3}}, \frac{0.069}{A_{4}}, \frac{0.05}{A_{5}}\right\} ; \\
K_{3} & =\left\{\frac{0.512}{A_{1}}, \frac{0.258}{A_{2}}, \frac{0.120}{A_{3}}, \frac{0.069}{A_{4}}, \frac{0.043}{A_{5}}\right\} ; \\
K_{5} & =\left\{\frac{0.479}{A_{1}}, \frac{0.251}{A_{2}}, \frac{0.153}{A_{3}}, \frac{0.069}{A_{4}}, \frac{0.042}{A_{5}}\right\}
\end{aligned}
$$$$
K_{2}=\left\{\frac{0.387}{A_{1}}, \frac{0.374}{A_{2}}, \frac{0.129}{A_{3}}, \frac{0.065}{A_{4}}, \frac{0.042}{A_{5}}\right\} ;
$$$$
K_{4}=\left\{\frac{0.386}{A_{1}}, \frac{0.374}{A_{2}}, \frac{0.128}{A_{3}}, \frac{0.065}{A_{4}}, \frac{0.043}{A_{5}}\right\} \text {; }
$$

From (4), it follows that there is no option dominating by all criteria, so the decision will depend on the importance of the criteria themselves. The coefficients of importance of the criteria $K_{1} \div K_{5}$ are as follows: $\alpha_{1}=0.334 ; \alpha_{2}=0.325 ; \alpha_{3}=0.254 ; \alpha_{4}=0.0462 ; \alpha_{5}=$ 0.0402. Therefore, when making a decision, the most important ones are energy $\left(K_{1}\right)$, environmental $\left(K_{2}\right)$, and economic $\left(K_{3}\right)$ criteria. Taking into account the importance of the criteria by formula (3), we obtain the following fuzzy sets: 


$$
\begin{aligned}
& K_{1}=\left\{\frac{0.565^{0.334}}{A_{1}}, \frac{0.199^{0.334}}{A_{2}}, \frac{0.113^{0.334}}{A_{3}}, \frac{0.069^{0.334}}{A_{4}}, \frac{0.05^{0.334}}{A_{5}}\right\}=\left\{\frac{0.826}{A_{1}}, \frac{0.583}{A_{2}}, \frac{0.483}{A_{3}}, \frac{0.409}{A_{4}}, \frac{0.368}{A_{5}}\right\}, \\
& K_{2}=\left\{\frac{0.387^{0.325}}{A_{1}}, \frac{0.374^{0.325}}{A_{2}}, \frac{0.129^{0.325}}{A_{3}}, \frac{0.065^{0.325}}{A_{4}}, \frac{0.042^{0.325}}{A_{5}}\right\}=\left\{\frac{0.735}{A_{1}}, \frac{0.726}{A_{2}}, \frac{0.514}{A_{3}}, \frac{0.411}{A_{4}}, \frac{0.357}{A_{5}}\right\}, \\
& K_{3}=\left\{\frac{0.512^{0.254}}{A_{1}}, \frac{0.258^{0.254}}{A_{2}}, \frac{0.120^{0.254}}{A_{3}}, \frac{0.069^{0.254}}{A_{4}}, \frac{0.043^{0.254}}{A_{5}}\right\}=\left\{\frac{0.844}{A_{1}}, \frac{0.709}{A_{2}}, \frac{0.584}{A_{3}}, \frac{0.507}{A_{4}}, \frac{0.45}{A_{5}}\right\}, \\
& K_{4}=\left\{\frac{0.386^{0.046}}{A_{1}}, \frac{0.374^{0.046}}{A_{2}}, \frac{0.128^{0.046}}{A_{3}}, \frac{0.065^{0.046}}{A_{4}}, \frac{0.043^{0.046}}{A_{5}}\right\}=\left\{\frac{0.957}{A_{1}}, \frac{0.956}{A_{2}}, \frac{0.909}{A_{3}}, \frac{0.882}{A_{4}}, \frac{0.865}{A_{5}}\right\}, \\
& K_{5}=\left\{\frac{0.479^{0.04}}{A_{1}}, \frac{0.251^{0.04}}{A_{2}}, \frac{0.153^{0.04}}{A_{3}}, \frac{0.069^{0.04}}{A_{4}}, \frac{0.042^{0.04}}{A_{5}}\right\}=\left\{\frac{0.971}{A_{1}}, \frac{0.946}{A_{2}}, \frac{0.928}{A_{3}}, \frac{0.899}{A_{4}}, \frac{0.881}{A_{5}}\right\} .
\end{aligned}
$$

Based on the results of fuzzy sets and according to formula (3), we obtain the following result:

$$
\widetilde{D}=\left\{\frac{0.735}{A_{1}}, \frac{0.583}{A_{2}}, \frac{0.483}{A_{3}}, \frac{0.409}{A_{4}}, \frac{0.357}{A_{5}}\right\} .
$$

Analyzing the solution obtained, we can conclude that the $A_{1}$ option is the most preferable over the others, as well as the weak advantage of the $A_{2}$ option over the $A_{3}$ option and the $A_{4}$ option over the $A_{5}$ option.

Thus, the following conclusions can be drawn concerning the results of the multicriteria assessment of the layout diagrams of biogas plants for the automated production of biogas in the agro-industrial complex:

1. The problem of optimal multicriteria choice of a biogas plant operating on the processing of solid organic waste can be considered in the form of a hierarchy with five main criteria based on fuzzy sets.

2. The motivation for the use of the developed methodology when choosing a biogas plant scheme is that almost always in automation, a description of a strict technological scheme is required and the preference for choosing one of the options is hampered by the fact that this choice depends on a very large number of difficult factors to be taken into account. But in contrast to this, it is possible to formalize non-strict preferences using a scale for the assessment of the intensity of relative importance, and get preliminary recommendations for choosing a rational layout of the BP.

3. A multicriteria decision support system can be adapted to the solution of the problem of choice, taking into account additional criteria (cost, variety of operation conditions, modular design, etc.). Moreover, this system does not change the order of options previously ranked by the method of analyzing the hierarchy of options, and when evaluating alternatives by criteria, both linguistic assessment and point assessment using the functions of membership are possible.

4. As the best solution, an alternative is chosen that simultaneously satisfies all the criteria to the maximum extent. As a result of the analysis of the model, it was revealed that preference should be given to options $A_{1}$ and $A_{2}$.

\section{Conclusion}

When choosing a biogas plant to automate the processing of agricultural wastes with the production of energy, fertilizers and feed additives, a number of design factors should be taken into account according to the classification of existing biogas plants and, depending 
on the specific requirements, a properly selected installation should be used on the farm, which could not only improve the environmental situation by utilizing and disinfecting the wastes, but also bring additional economic income. The main hardware modules of such a $\mathrm{BP}$, as the resulting solution $\tilde{D}$ shows, are biogas plants with modules for preparing and loading a substrate into a bioreactor and heating a substrate, as well as bioreactors with a blender for anaerobic digestion of a substrate (organic wastes), a gasholder for collecting and storing biogas, related to the first option of the investigated BP. The selected structural and functional scheme meets the requirements for the development of standard solutions for automation, which contributes to the replication of control systems for the same type of units, the improvement of the environmental situation by utilization and disinfection of wastes and the provision of additional economic income.

\section{References}

1. E. Kobyakova. Agricultural sciences and agro-industrial complex at the turn of the century. Classification and review of existing biogas plants, 5, 320-434 (2014)

2. Alternative energy of the Krasnodar Territory: problems and development prospects URL: https://smi.kuban.info/communikacia/546-alternativnaya-yenergetikakrasnodarskogo-kraya-problemy-i-perspektivy-razvitiya.html

3. Biogas plant in Krasnodar URL: https://www.newchemistry.ru/letter.php?n_id=8875

4. Bioreactor and other equipment for processing manure into biogas: types, principle of operation, popular models URL: https://rcycle.net/navoz/oborudovanienavoz/bioreaktor-i-drugie-ustanovki-dlya-pererabotki-v-biogaz

5. L. Blinova. Problems of modern economy : materials of the II International Scientific Conference. Biogas plants as an alternative source of energy in the agro-industrial complex of the Russian Federation, 41-44 (2012)

6. A. Rothstein. Project and program management. Multi-criteria selection of a brand project using fuzzy paired comparisons of alternatives, 2, 138-146 (2006)

7. T. Saaty. Decision-making. Hierarchy analysis method, 278 (1993)

8. R. Bellman. Issues of analysis and decision-making procedures. Decision making in vague conditions, 172-215 (1976)

9. V. Zakharov. On the choice of methods for constructing membership functions for formalizing decision-making problems URL: http://www.smolensk.ru/user/sgma/MMORPH/N-12-html/borisov/zakharov/zakharov. htm

10. E. Lubentsova, E. Ozhegova, V. Lubentsov, E. Shakhray and G. Masyutina. Modern high technologies. Method of matching paired comparison matrices based on components of their maximum eigenfrequency numbers, 7, 78-83 (2020) 